\title{
Comment on Neuromyelitis Optica: Potential Roles for Intravenous Immunoglobulin
}

\author{
Denis Bernardi Bichuetti • \\ Enedina Maria Lobato de Oliveira
}

Received: 18 September 2012 / Accepted: 24 September 2012/Published online: 30 September 2012

(C) Springer Science+Business Media New York 2012

Dear Dr. Thomas A. Fleischer

Editor, Journal of Clinical Immunology

We read with much enthusiasm the essay by Dr. Wingerchuk on the plausibility for the use of IVIG in preventing relapses in patients with NMO (Epub 2012 Sep 14), an interesting alternative for the invasive procedure that is plasma exchange.

We would like to share with you and Dr. Wingerchuk our work presented at this years AAN meeting, reporting the effects of IVIG used in 8 patients with relapsing NMO (Neurology April 22, 2012 78:P04.141). There were 7 women and one man with mean age of 30 years and mean disease duration of 7.6 years; 5 were positive for the NMO-IgG. Reasons for IVIG indication were either severe relapse not improving after $5 \mathrm{~g}$ IV methylprednisolone and inefficacy to reduce ARR or EDSS worsening on adequate immunosuppression with azathioprine and prednisone. One patient received the drug soon after a cluster of relapses upon diagnosis. We used the same dose as for other immune mediated neurological diseases, i.e., $0.4 \mathrm{~g} / \mathrm{kg} /$ day for 5 consecutive days, and patients received two to ten cycles of IVIG, usually 2 months apart. We observed a mean ARR reduction from $1.8( \pm 1.6)$ to $0.1( \pm 0.2)$ and mean PI from 1.5 $( \pm 1.6)$ to $0.9( \pm 0.6)$. There were no adverse effects from the use of IVIG, but unfortunately one patient died due to severe encephalitic and brainstem relapse while on therapy.

The rationale for using IVIG in these patients were the same discussed by Dr. Wingerchuk, stimulated by the fact that plasma exchange is not reimbursed by the public health care system in Brazil for the treatment of NMO. We understand that NMO is a rare disease, and most of the treatment strategies remain based on case series and expert opinion, and hope that the use of IVIG can be further evaluated in larger series in order to prove its efficacy as an alternative for plasma exchange, or even its use upon diagnosis as an "induction therapy".

Yours sincerely, Denis Bernardi Bichuetti

Enedina Maria Lobato de Oliveira

D. B. Bichuetti $(\bowtie) \cdot$ E. M. L. de Oliveira

Neuroimmunology Clinic, Universidade Federal de São Paulo,

São Paulo, SP, Brazil

e-mail: denisbichuetti@globo.com 